IMANTS MEŽARAUPS

Riga Teacher Training and Educational Management Academy, Latvia

\title{
ANALYTICAL METHODS IN THE PROCESS OF LEARNING MUSIC
}

\section{SUMMARY}

Introduction. Learning to perform any new musical work is a multi-dimensional task for any musician, young or old, experienced or novice. In most academic situations (as opposed to improvisatorial situations typical for jazz and popular music), the musician must acquire all of the needed musical information from the notated score, and translate that to actual performance. This process can be expedited and made more accurate if analytical methods are employed in studying the musical score.

The Aim of the Study. To briefly illustrate analytical methods that have been proposed by music theorists, but here not for the sake of music theory as such, but rather to enhance the learning process for any practicing musician. Analysis can be a practical tool that enables musicians to learn more quickly.

Materials and Methods. Study of literature by prominent music theorists; analysis of practical experience acquired as a teacher of music.

Results. The examination of analytical methods shows how musical information can be more easily grouped, filtered, ordered, and re-structured. This information can be a useful tool for any music teacher and performer.

Conclusions. Music can be learned without much analysis, but then the process of learning will be slower and less insightful. Analysis can offer clues as to how one can better interpret music and perform with greater confidence, understanding, and emotional freedom.

Keywords: analytical methods, structural levels, musical processes, grouping

\section{INTRODUCTION}

In most situations in which a musician, young or old, novice or professional, needs to learn to perform a new piece of music, the learning process is centered around the notated musical score. There are exceptions, especially in the jazz and popular music styles, in which making music by ear is more pertinent, but for the most part, the ability to translate musical notation into actual performance, with precision, confidence, and personal emotional substance, is every musician's primary task. It is possible to approach any musical score as a chronological sequence of notes that need to by played or sung. However, music theorists have shown many analytical methods that reveal various levels of musical structure. If a performer invests some time in applying these theoretical, analytical methods, he/she will not only save much time in learning the piece of music more quickly, but will also have a much deeper insight into what the music is trying to convey. All music is a combination of organized structure and emotional expression, the proportions of each varying according to the musical style and compositional technique. For example, if a piece of music is highly aleatoric, then the arguments in favor of analysis must be placed in an entirely different perspective than, say, if a musical work is highly organized as a composed structure.

Learning to perform a piece of music always involves memory and organizational skills. The more a performer can filter out complexities that obscure the fundamental structure of a musical work, at first, and perceive large-scale structural parameters, the more quickly he/she will be able to comprehend the work as a whole, and perhaps gain a few learning shortcuts along the way.

In Latvia, $20^{\text {th }}$ century analytical methods are not well known or used in practice. But furthermore, in the opinion of this author, modern analytical methods that are traditionally aimed 
at academic music could be quite useful in the study of jazz. Therefore, while it might seem that this study mixes jazz with academic music, this is precisely the aim. Jazz can benefit from academic music analytical methods.

\section{AIM OF THE STUDY}

To briefly illustrate analytical methods that have been proposed by music theorists, but here not for the sake of music theory as such, but rather to enhance the learning process for any practicing musician. Analysis can be a practical tool that enables musicians to learn more quickly.

\section{MATERIALS AND METHODS}

Music theorists have given us a legacy of analytical methods that enable us to understand the processes and structures that define musical works of many styles and historical periods. However, these methods are typically studied by composers and next-generation music theorists, but not by performing musicians. The practical applications that analyses offer the performing musician are too often neglected. The more a performer commits some time to musical analysis, the better and quicker he/she will be able to grasp what is essential for preparing a convincing performance.

Musical notation is the written symbol that conveys musical information that must be converted into sound by the performer. Notation contains information on many levels, and often the structural levels are such that it is difficult to see the forest because there are so many trees. If an analysis is done in such a way as to filter out distractions and to find ways of organizing components, then the learning process can be expedited.

As an analogy, let us imagine that we must quickly learn and commit to memory a sequence of numbers: 7891011121 314. At first glance, it seems that the groupings are random, making the learning task rather difficult. However, upon a brief analysis we might notice that these numbers can be re-grouped: 7891011121314 . And if we combine this simple information with the grouping of 2, 4, 4, and 3 digits, then the pattern can be remembered quickly and easily (Larson, 1992).

Similar situations often arise in musical notation. The patterns of structurally significant notes might be quite simple, but they can be obscured by ornamental and decorative notes that create musical textures but interfere with our perception of basic structures. It must be emphasized that these decorations form the essence of musical beauty; basic musical structure would be no more enjoyable than looking at the bare steel framework of a building that is under construction. The architectural detail gives birth to individuality and beauty.

Some analytical endeavors are quite obvious. For example, if a musician discovers that the form of a piece of music is ABA, then the recapitulation of the A section need not be learned anew. If it is a varied recapitulation (ABA'), then the details that are varied will need to be taken into account. If there is sequencing or repetition by transposition, then the recognition of these will facilitate the learning of the performance.

However, musical processes are often more elaborate, and there might be complications and challenges within sections of musical works as they unfold. The observations of some noteworthy music theorists will offer strategies in better perceiving musical forms on different structural levels.

Heinrich Schenker (1868-1935) was a highly influential music theorist (Schenker, 1969). A native of Austria, he studied in Vienna with Anton Bruckner, and became a practicing chamber musician, teacher, editor, and theorist (Sadie, 1988). His theoretical work culminated with the Five Graphic Music Analyses, in which he proposed a system of unraveling music's structure through Schichten, musical layers of background, middleground, and foreground. In his concept of Urlinie (fundamental melodic line) and Ursatz (fundamental composition), harmony and counterpoint are combined at the deepest level of musical structure. While the Urlinie traces the melodic motion of the upper voice (or primary melodic line) over the course of an entire 
composition, the Ursatz shows the arpeggiation of the bass line through tonic, dominant, and tonic functions, together providing a two-part structural framework. The concept of structural levels provides for a hierarchical differentiation of musical components, which establishes a basis for describing and interpreting relations among the elements of any composition. The foreground provides the most textural musical detail, the "composing" out of the structural material, which is where the originality and uniqueness of a musical work is to be found. Each stage in Schenker's reductions removes a layer or layers of structurally less important notes, revealing an increasingly bare skeleton of musical structure. In Schenker's view the total work at all levels, not only the background level, is the object of study and aesthetic perception (Schenker, 1969).

Schenker sought (Schenker, 1969) to provide graphic analyses for which very little verbal explanation would be needed. His analyses show larger and smaller note values and noteheads, usually connected by beams, brackets, or ties, and the hierarchies of notes, their structural significance on each level and connections between them, are immediately visually perceptible. Sometimes important notes form, on a broad scale, arpeggiations of a single triadic harmony, giving a composition large-scale tonal coherence. Sometimes the large-scale structural notes form step-progressions, an important idea elaborated by Paul Hindemith (Hindemith, 1942) in his theoretical work.

What Schenker's analyses reveal is that such concepts as passing tones, neighboring tones, suspensions, etc., which are traditionally taught in music theory as melodic non-chord tones in the context of a single harmony, can be applied to melodic tones and entire harmonies on several structural levels. So, for example, if within a small musical phrase we hear harmonic motion I-V6-I, on a larger level, considering a longer musical statement, the V6 will disappear, because on the larger structural level it is not significant, it merely prolongs the "area" of tonic harmony. For melodic motion, the progression of hierarchically "important" notes at various levels of musical structure can be perceived either as prolongations (if a note is repeated), step progressions, or arpeggiations. These notes might be separated by many measures of musical activity, but if they stand out because of their range, duration, dynamic emphasis, or some other factor, audible structural connections can be heard. Hearing such connections can only facilitate learning to perform a new piece of music.

A study of Schenker's (Schenker, 1969) analytical levels of background (the most fundamental structural level) to middleground to foreground is somewhat like watching the construction of a building. First we see the columns, beams and girders that form the structural framework, even though later we might not see them at all. Then we see bricks set into place forming walls, and so on, ending with windows, doors, and bits of architectural trim that lend beauty to the building. Examining the details that are beautiful is a gratifying experience, but it will not necessarily help us to understand why the building is able to stand and does not collapse. Probably the most productive study of Schenker's graphs would be to go backwards, starting at the foreground, because that is closest to what we actually hear during the performance of a musical composition, and finishing with the background, which is so simplified and remote from the actual musical texture, that we can only understand how we got there if we look at each analytical layer one by one. This would be like removing the architectural details from a building, then removing the bricks, until we are left with just a bare skeletal frame.

Felix Salzer (Salzer, 1982) was a student of Schenker, and his theoretical masterpiece is the book Structural Hearing - Tonal Coherence in Music. Salzer sought to extend Schenker's ideas so as to enhance the perception of musical structure on various hierarchical levels, as Schenker had done, but to do so in such a way that these principles could be applied to any musical style of any historical period. While Schenker's work was limited to the common-practice period (Baroque, Classical, and Romantic), in which tonality exerted supreme harmonic force, Salzer extended the analytical method in such a way that music ranging from folk music to Medieval 
and Renaissance music to $20^{\text {th }}$ century music could be analyzed and perceived. Furthermore, he expanded Schenker's (Schenker, 1969) analytical methods within the realm of tonal music so as to explain tonal processes and their perception in far greater detail.

Salzer's masterpiece is in two combined volumes: the first is a systematic, detailed explanation of his theoretical ideas, stemming from those of his mentor, replete with references to the second volume, which is a compilation of musical excerpts and graphic analytical reductions of them. What is truly impressive and remarkable is the range of music that Salzer explores he applies his methods to Gregorian chant, music of the Medieval, Renaissance, Baroque, Classical, and Romantic periods, as well as to Debussy, Bartok, Stravinsky, and Hindemith. He provides compelling illustrations that his analytical approach can be used to understand a much wider range of musical styles than any traditional approach could offer, such as Roman numeral harmonic analysis.

If a musician can perceive the structural tones and harmonies on a level similar to Schenker's middleground (Schenker, 1969), or one of Salzer's (Salzer, 1982) analyses, he/she can perceive the organizing structure of the music and feel what is important to bring to the forefront in musical interpretation. One needs to retain a large-scale memory for stable, structural tones, and how they might progress, not note-by-note, but over a larger structural span.

Similarly, if a musician must perform a relatively complex melody, chances for success will be greater if:

1. The performer can structurally analyze the melody, even briefly;

2. Structural connections can be made between tones (over a larger area than between adjacent tones) that form large-scale step progressions and/or arpeggiations;

3. Other notes can be recognized as processes - that is, stepwise motion (diatonic or chromatic) or arpeggiations, with attention being paid to endpoints - tops and bottoms of the process.

Picture 1 illustrates this author's approach to analyzing a seemingly complicated jazz standard melody, Duke Ellington's "I Let a Song Go Out of My Heart", using the analytical methods of Schenker and Salzer (see Picture 1). Surprisingly organized and symmetric structural elements emerge, and an awareness of them facilitates learning to perform this song.

Picture 2 shows a brief excerpt from a bridge section of the jazz standard "Take the " $A$ " Train", which in real time flies past at a daunting speed (see Picture 2). Whether the task be to listen and transcribe, or to execute the passage as a performer, it will be simplified if the musician does not attempt to perceive the stream of notes as such, but rather, as a process (Berg, 1990). One is a diatonic scale upwards, and the other is a chromatic descent. One needs to note only the endpoints, and then the swiftly flying notes in between can be filled in. 
Paul Hindemith (Hindemith, 1942), in his masterful book The Craft of Musical Composition - Book 1: Theory, outlines various means of musical analysis that can be applied to any musical style period. He gives examples ranging from Gregorian chant to the atonal music of the Second Viennese School. While certain aspects of his analytic methods were clearly meant to be scrutinized by theorists and composers, perceive melodic process, not note content some aspects would be very useful for all performers, especially the melodic step-progression analysis. Observing the stepwise progression of upper and lower melodic tones helps to make sense of melodies that otherwise seem complicated by large leaps and arpeggiations. Tracing the upper and lower boundaries of a tune such as the jazz ballad "Misty" shows an organic cohesiveness that makes this otherwise tricky melody easier to learn to sing.

Another significant innovation by Hindemith (Hindemith, 1942) is the development of a system of classifying harmony with Roman numerals and Arabic numbers, not to indicate scale functions, as in traditional harmonic analysis, but to classify chords according to their acoustic stability or instability. His analysis system makes it possible to categorize literally any combination of pitches, from simple triads to atonal clusters, so that harmony of any time period could be analyzed. His analytical examples show what he calls "harmonic fluctuation"how harmonies change, or fluctuate, with regard to their relative dissonance or consonance. Hindemith's analyses give significant clues as to how a musician might perform a complicated, perhaps atonal phrase, with regard to dynamics and musical expression. Without a system such as Hindemith's (Hindemith, 1942), a musician learning a modern, post-tonal piece of music may be bewildered by the confusing harmonies.

A very enlightening extension of Schenker's and Salzer's ideas can be found in Structural Functions in Music by Wallace Berry (Berry, 1976). In this work he thoroughly examines all of the musical parameters of melody, harmony, rhythm, texture, etc. throughout a wide range of stylistic time periods. Particularly encouraging are his analytical observations as they pertain to the most dauntingly complex modern works, such as Le Marteau sans Maitre by Pierre Boulez. An excerpt from the third movement is shown along with Berry's analytical outline in Picture 3 (see Picture 3). An awareness of this outline greatly facilitates the task of learning to sing this intimidating, difficult melody.

However, the analytical principles demonstrated by Schenker (Schenker, 1969), Salzer (Salzer, 1982), and Berry (Berry, 1976) can also give us insight into how to interpret even the most familiar classics. Picture 4 shows a very well known theme by Mozart (see Picture 4). A traditional harmonic analysis does not tell us much about how we should shape this opening phrase; all we see is that the tonic harmony moves to a neighboring dominant $4 / 3$ chord and returns to the tonic. A Schenkerian graphic analysis, however, reveals that while the rising tonic

Picture 3. Analytical approach to conquering extremely difficult musical material

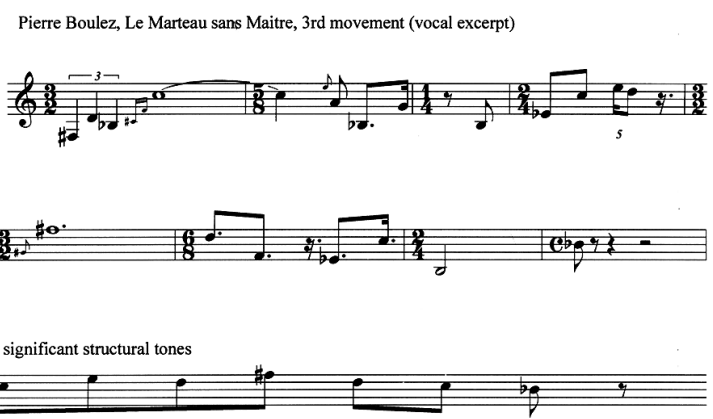


triad is melodically not significant - it is Picture 4. Analytical clue for musical a prolongation of the tonic-he motion to the leading tone and back is structurally more significant, and therefore a legato phrase connecting the notes $\mathrm{C}-\mathrm{B}-\mathrm{C}$ with a crescendo and diminuendo would be the most appropriate interpretation for performance. This is but a very simple example; this technique can be applied on many structural levels, as the theorists show us.

Parallels can be (and have been) drawn with regard to harmonic processes. An awareness of key tonal centers and of harmonic function as structural or "prolongational" leads to an enhanced approach to learning to perform any new piece of music. Learning a large-scale musical form, such as a sonata movement, will be enhanced by a previous analysis of its tonal plan. Knowledge of harmonic processes - diatonic stepwise, chromatic, circle-of-fifths, etc. - will facilitate the learning of smaller-scale sections of music. Even for a singer or melody-instrument soloist, knowledge of the harmonies that surround the solo part will give important clues as to how to more expressively interpret one's part. For example, melodic motion might be static at the moment that a significant harmonic change takes place; this would indicate that the soloist should place expressive emphasis on this moment, even though the melody itself does not suggest this. Or vice versa: perhaps a large melodic leap might come at a harmonically insignificant moment, therefore suggesting that this leap should not be overemphasized, but rather, made as smooth as possible.

Because modern, post-tonal music presents particularly difficult challenges, investigating some practical analytical methods proposed by specialists in this field can give useful insights as to how this music should be understood and performed (Friedmann, 1990; Kostka, 1990; Straus, 1990). The more a musician perceives and understands structural connections, the more convincing his/her performance will be.

\section{RESULTS}

During the last years of my teaching, I have increasingly emphasized the awareness of the theoretical concepts presented here among my students. I have seen that a conscious perception of musical structure as the result of analysis enables students to learn more quickly and with greater precision. Precision gives them freedom to be more creative in emotional and interpretative ways. If this is true for students, then it should be true for any performing musician, student and professional alike. This is applicable to academic music as well as jazz.

\section{CONCLUSIONS}

Music can be learned without analysis, just as a sport can be played without strategy. However, knowledge of the rules and strategies of any sports game will only enhance the results of the athlete. In this day and age, athletes spend more and more time watching video recordings of previous matches and analyzing the strategies of their opponents. Why should musicians not spend some time analyzing the very substance of what they are learning to perform, especially if it is something unfamiliar to them? Analysis improves understanding, and understanding gives a performer freedom to interpret and to convey one's deepest emotions. Conveying a heartfelt emotion through music cannot be genuine without understanding the structural content of the music itself. Analytical methods are underused in academic music, but they should also be applied to jazz. While Schenker, Salzer, and Hindemith were not interested in jazz specifically, they did indeed aim to provide methods that could be used to any style in music. Therefore, an insight provided by them that might help one understand how to better perform a work by Mozart could also be applied to Duke Ellington. 


\section{REFERENCES}

1. Berg, S. (1990) Jazz Improvisation: The Goal-Note Method. Delevan, New York: Kendor Music, Inc., 247 p.

2. Berry, W. (1976) Structural Functions in Music. New York: Dover Publications Inc., 447 p.

3. Friedmann, M. L. (1990) Ear Training for Twentieth-Century Music. New Haven: Yale University Press, $211 \mathrm{p}$.

4. Hindemith, P. (1942) The Craft of Musical Composition, Book 1: Theory. London: Schott \& Co Ltd., 223 p.

5. Kostka, S. (1990) Materials and Techniques of Twentieth-Century Music. Prentice Hall: Englewood Cliffs, $337 \mathrm{p}$.

6. Larson, S. (1992) Species Counterpoint: A Study of Musical Expression (Unpublished manuscript).

7. Sadie, S. (Ed.) (1988) The Norton/Grove Concise Encyclopedia of Music. London: Macmillan Press Ltd, $850 \mathrm{p}$.

8. Salzer, F. (1982) Structural Hearing - Tonal Coherence in Music. New York: Dover Publications, 349 p.

9. Schenker, H. (1969) Five Graphic Music Analyses. New York: Dover Publications, 61 p.

10. Straus, J. N. (1990) Introduction to Post-Tonal Theory. Prentice Hall: Englewood Cliffs, 218 p.

Lecturer Dr. mus. arts Imants Mežaraups

Riga Teacher Training and Education Management Academy

Address: Imantas 7. linija 1, Riga, LV-1083, Latvi

Private Address: Ernestines iela 18A - 15, Riga, Latvia LV-1046

Mob. phone: +37129421760

E-mail: imezaraups@yahoo.com 